\title{
Intelligently programming the thread production on the external cylindrical surfaces for the Fanuc control system.
}

\author{
Peter Michalik ${ }^{1}$, Michal Hatala ${ }^{2}$, Dusan Mital ${ }^{3}$ \\ peter.michalik@tuke.sk ${ }^{1}$, michal.hatala@tuke.sk ${ }^{2}$, dusan.mital@tuke.sk ${ }^{3}$
}

1,2,3 Technical University of Kosice, Department of Automotive and Manufacturing Technologies, Faculty of Manufacturing Technologies with seat in Presov, Bayerova 1, 08001 Presov, Slovak Republic

\begin{abstract}
This article deals by the process of programming the production of external metric threads on outer cylindrical surfaces by means of the workshop programming for the Fanuc control system on the Leadwell T5 lathe. Described is the procedure of filling the windows for the geometric parameters needed to define the dimensions of the threaded groove and the tool. Further working windows for cutting conditions, spindle speed and tool feed rate.
\end{abstract}

Keywords: metric threads, programming, Fanuc control system

\section{Introduction}

Workshop programming was developed at the beginning of 1980 and is Expanded in many areas (machining operations, maintenance workshops, prototype workshops, etc.). Workshop programming the $\mathrm{CNC}$ is developed to address the low efficiency of manual programming in $\mathrm{G}$ mode and CAM offline programming software [1], [7]. Good workshop programming is intuitive, simple and capable of simple programming of complex components. Shop programming on $\mathrm{CNC}$ becomes very efficient programming a tool for many machine workshops and the plants they produce parts in small or medium-sized production bins. Workshop programming has become more successful thanks to progress in the computing technique [2]. Early workshop programming operations are very similar to DOS on PC. The user interface was text based on hardware limitations and was not intuitive [6]. For example, it is difficult to describe geometry by text, forcing the operator to do well he understood geometric nomenclature [3].

The Fanuc control system uses the Intelligent Programming System, labeled Manual Guide i. It is modular, has a graphical user interface. It contains a basic system with turning and milling modules, which have a unified structure and a user interface despite different technologies. [5] 


\section{Material, drawing of thread component, procedure of intelligently programming thread machining}

The component was made of duralumin ENAW2007. It has a good workability. Dimension of produced thread component see Figure 1 are length $13 \mathrm{~mm}$ and metrical thread 16 . Was used outer thread right tool with cutting plate from sintered carbide [4].
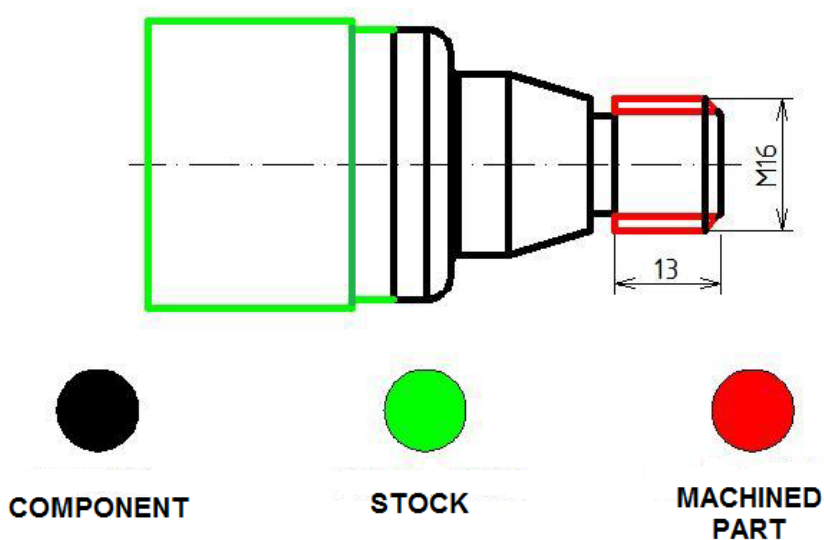

COMPONENT

STOCK

PART

Fig. 1. Dimension drawing of produced component thread

Spindle speed was used $1050 \mathrm{rpm}$ and speed feed $2 \mathrm{~mm} / \mathrm{rev}$.

At the beginning of programming in mode editing see Figure 2 is necessary creation new CNC program.

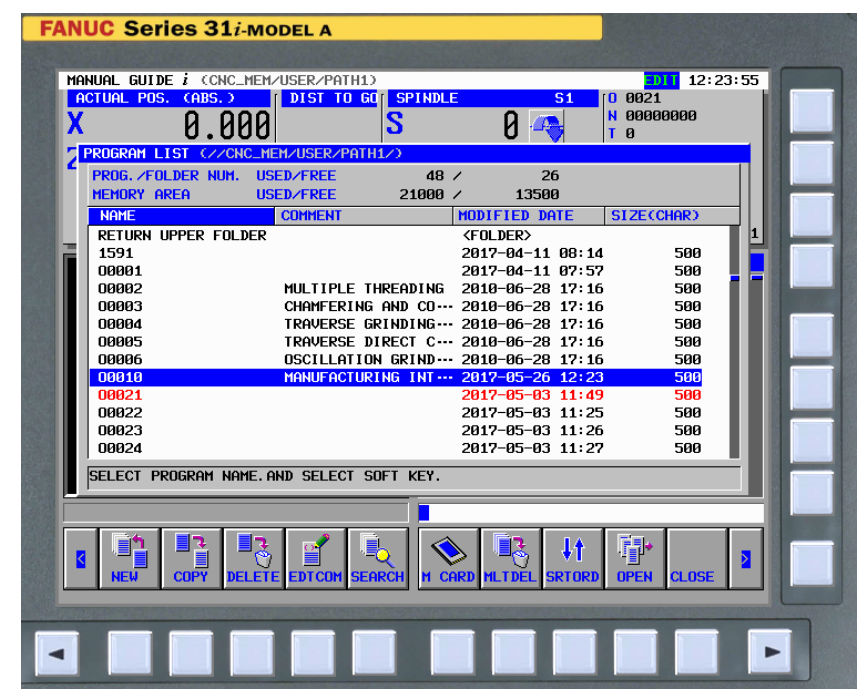

Fig. 2. Creation new CNC program 
In selection software's buttons following selection cycle for turning operation see Figure 3.

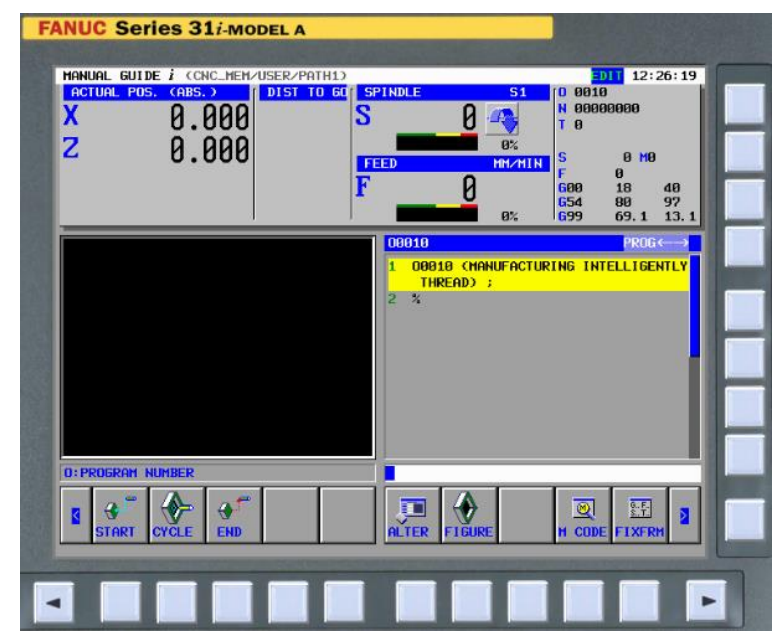

Fig. 3. Selection command Cycle

In necessary window were selection near shape of stock see Figure 4 for simulation in graphical environment Guide i.

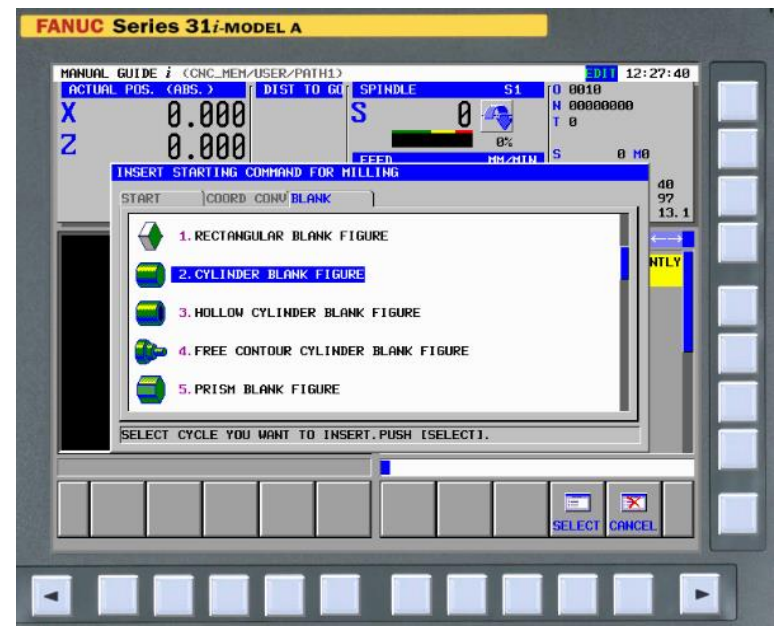

Fig. 4. Cylinder stock selection for simulation

After selection right shape of stock were defined his diameter a length from production drawing. Control system generation in CNC program function G1900 see Figure 5. 


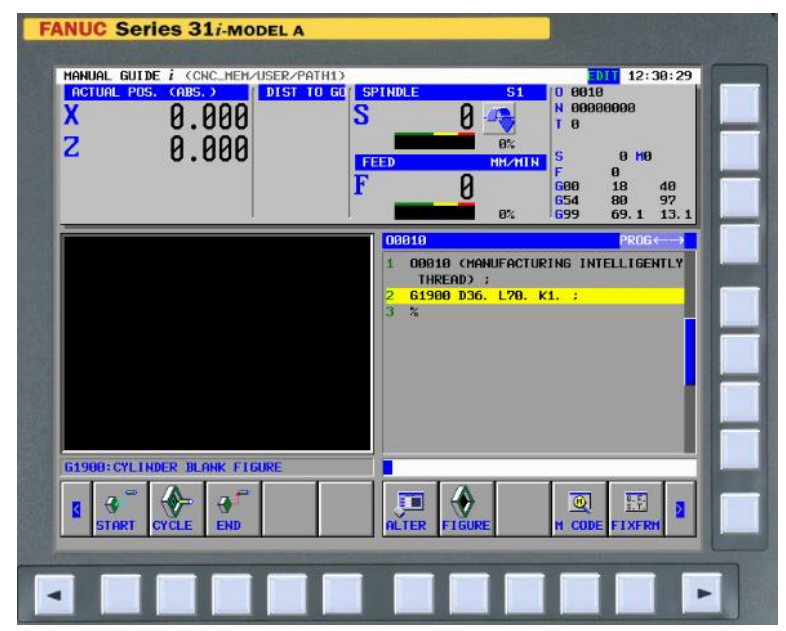

Fig. 5. Block dimension of stock in program

Working window Insert turning cycle see Figure 6 offer selection threading outer or inner thread.

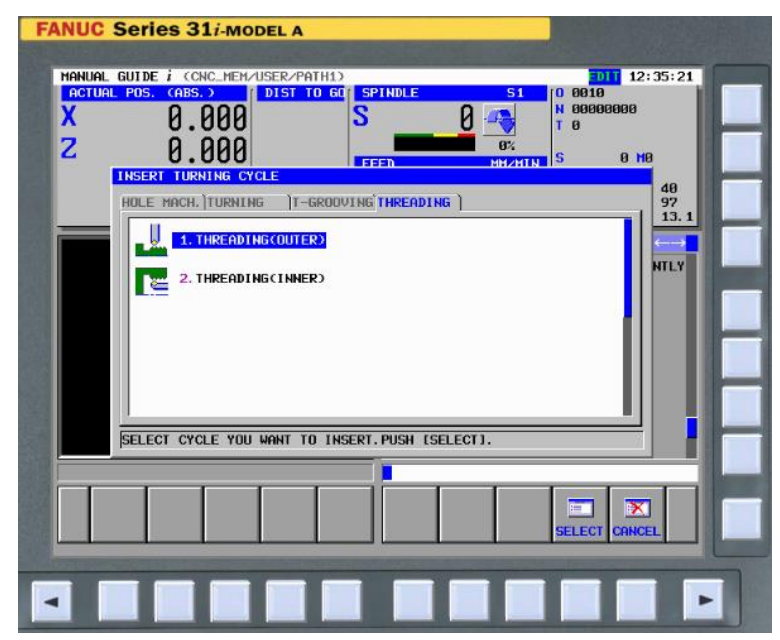

Fig. 6. Operation selection threading outer

In working window Cutting condition from Threading outer see Figure 7 is necessary define cutting method, finish amount, number of finishing, cut tape and cut depth number. 


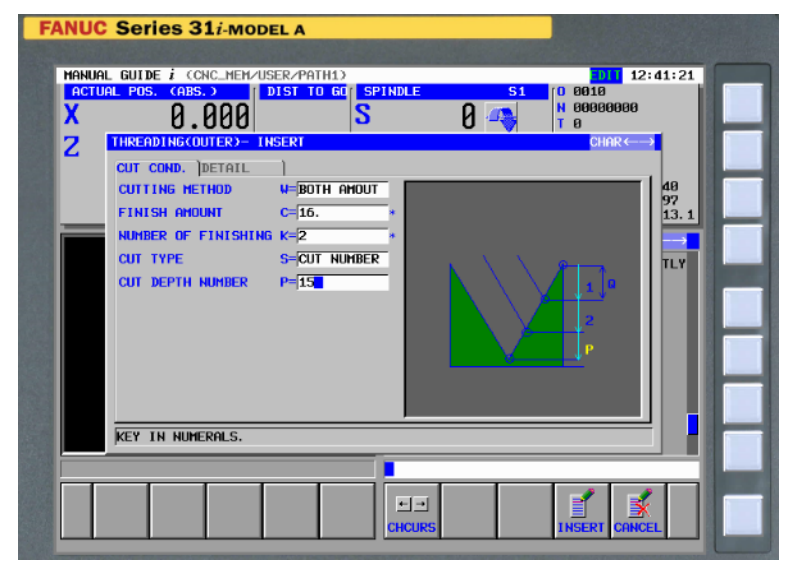

Fig. 7. Window of cutting condition threading outer

In working window Detail from Threading outer see Figure 8 is necessary define approach motion, surface clearance, entrance clearance, and exit clearance.

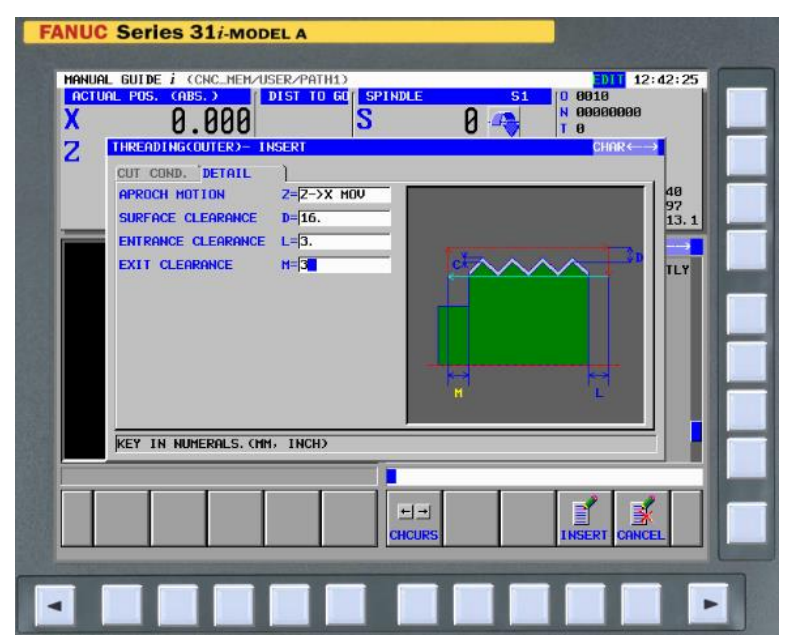

Fig. 8. Window of detail threading outer

Following selection cylindrical metric thread see Figure 9. 


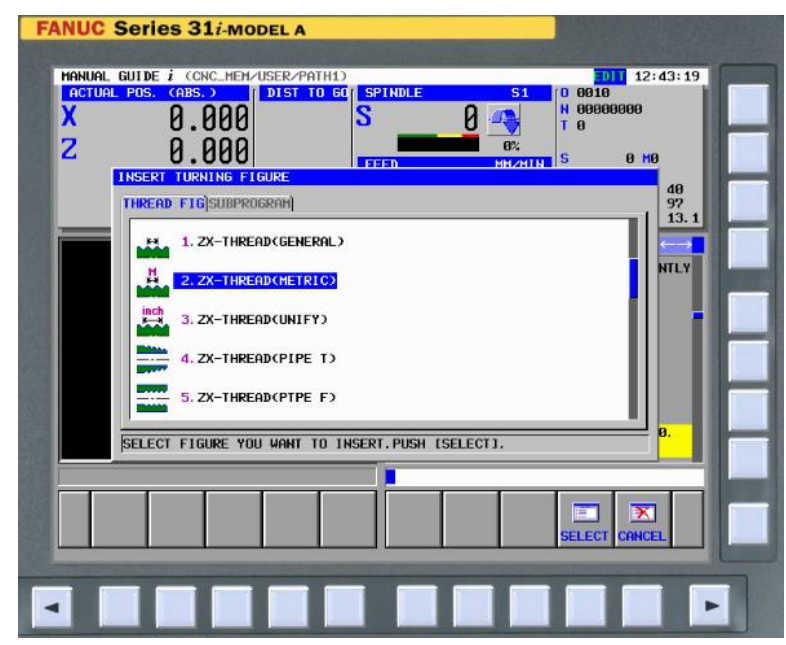

Fig. 9. Window thread metric selection

In window thread metric see Figure 10 were specified figure type, thread diameter, start point, lead, length, thread depth, multiple input type and thread number of screw.

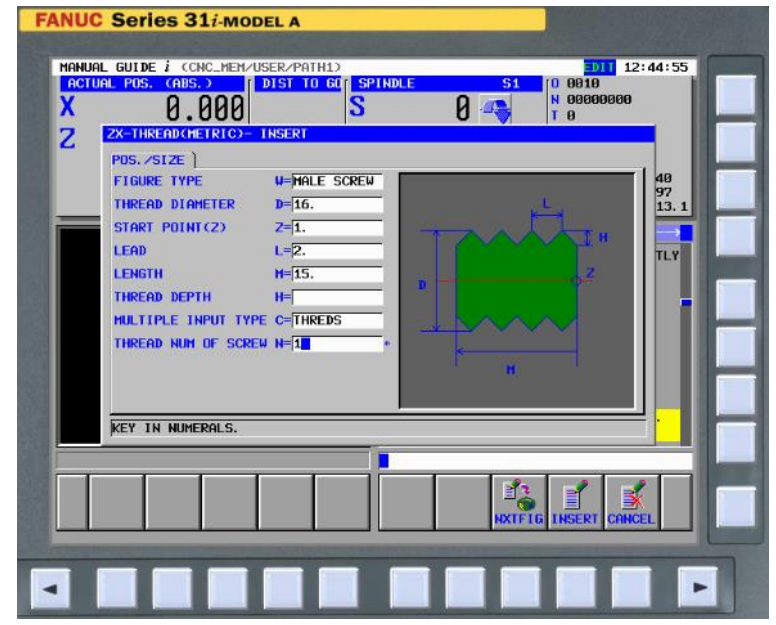

Fig. 10. Parameters for window thread metric

Last step after production of metric thread on machine Leadwell T5 were simulation o CNC program in mode single block see Figure 11. 


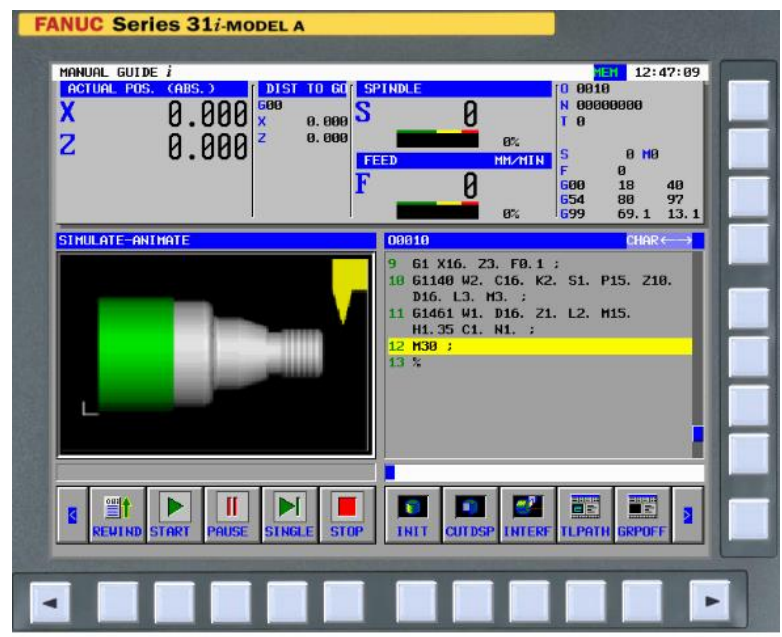

Fig. 11. Simulation production of metric thread

Before starting production on the Leadwell T5 Lathe see Figure 12, it is necessary to set the zero point of the component, measure the geometric characteristics of the tools and refine the $\mathrm{CNC}$ program.

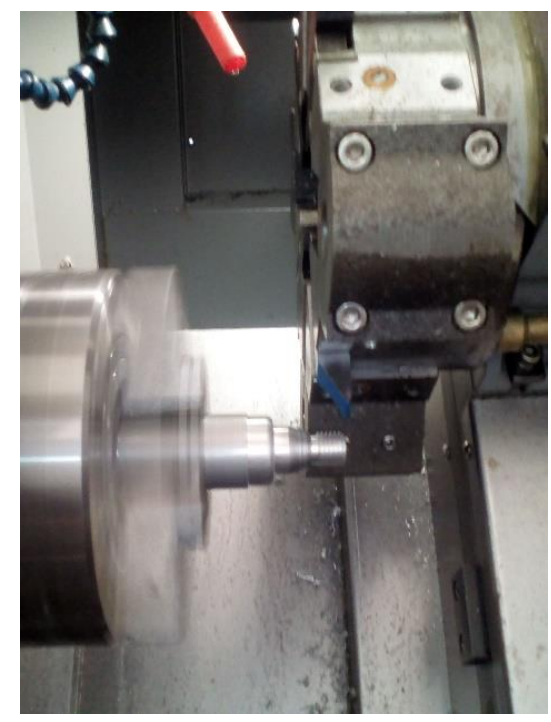

Fig. 12. Production thread on the Leadwell T5 


\section{Conclusions}

Workshop programming is suitable for operations that produce a wide assortment of components in single and small-lot production conditions. The advantage is that the operator very often executes the control program directly in the machine's control system. Also, select the tool and method of clamping the blank, verify and optimize the finished control program. The disadvantage is that it cannot be interfered with in the generated block of the program. It is necessary to reopen the work window for the operation to change the technological parameters and re-generate the block of program. Workshop programming can significantly boost production productivity in these plants. End-users will certainly consider using workshop programming on these machines as well. Worksheet programming is a bit more challenging than $\mathrm{G}$ code programming. It is recommended that the operator first acquires $\mathrm{G}$ code programming. Such trained CNC operators can greatly improve machine production. Today's workshop programming already takes me more from the Microsoft Windows graphical operating system and the entry and editing of the control program are all easier. Functions widely used in today's unreachable CAM software, Three-dimensional graphical interpretation already associated with the programming conversation system.

\section{Acknowledgement}

This work is a part of research project VEGA 1/0619/15 and VEGA 1/0492/16.

\section{References}

[1] Michalik, P., Zajac, J., Duplák, J., Pivovarník, A.: CAM software products for creation of programs for CNC machining, Lect. Notes Electr. Eng. pp. 421-425 141 (2011)

[2] Novák-Marcinčin, J., Török, J., Janák, M., Novakova-Marcincinova, L.: Interactive Monitoring of Production Process with Use of Augmented Reality Technology, Appl. Mech. Mater. pp.19-26. 616 (n.d.)

[3] Michalik, P., Zajac, J., Hatala, M.: Programming CNC Machines Using Computer-Aided Manufacturing Software, Adv. Sci. Lett. 19 pp. 369-373, (2013)

[4] Duplák, J., Panda, A., Kormoš, M., Pandová, Jurko, S.: Evaluation of T-vc dependence for the most commonly used cutting tools, Key Eng. Mater. pp. 278-285, 663

[5] Cep, R., et al.: Ceramic cutting tool tests with interrupted cut simulator, in: P. of I.C. on I.T. Praha (Ed.), IN-TECH 2010, pp. 144-148.,(2010)

[6] Novak-Marcincin, J., Novakova-Marcincinova, L., Barna, J., Janak, M.: Application of OF FDM rapid prototyping technology in experimental gearbox development process., (1986)

[7] Balog, M., Knapčiková, L., Husár, J.: Plánovanie v strojárskej výrobe, Tribun EU., Brno. ISBN 978-80-263-1078-5, (2016) 